\title{
Serum CA19-9 Level is Correlated with Liver Inflammation, Cirrhosis, and Poor Prognosis after Curative Resection in Hepatitis B-related Hepatocellular Carcinoma
}

\section{Wei Zhang ( zhangweitjch@163.com )}

Tianjin Medical University Cancer Institute and Hospital https://orcid.org/0000-0002-2439-6076

\section{Ying-Ying Wang}

tianjin medical university cancer institute and hospital

\section{Bo Yang}

tianjin cancer institute and hospital

\section{Lu Chen}

tianjin medical university cancer institute and hospital

\section{Ze-Wu Zhang}

tianjin medical university cancer institute and hospital

\section{Guang-Tai Cao}

tianjin medical university cancer institute and hospital

\section{Xiao-Yu Huang}

tianjin medical university cancer institute and hospital

\section{Guang-Hao Li}

tianjin mecical univeristy cancer institute and hospital

\section{Hui-Kai Li}

tianjin medical university cancer institute and hospital

\section{Yun-Long Cui}

tianjin medical university cancer institute and hospital

\section{Qiang Wu}

tianjin medical unversity cancer institute and hospital

\section{Ti Zhang}

Tianjin meical university cancer institute and hospital

\section{Tian-Qiang Song}

tianjin medical university cancer institute and hospital

\section{Qiang Li}

tianjin medical unversity cancer institute and hospital 
Research article

Keywords: carbohydrate antigen 19-9; hepatocellular carcinoma; a-fetoprotein; survival; inflammation Posted Date: June 30th, 2020

DOI: https://doi.org/10.21203/rs.3.rs-35605/v1

License: (c) (i) This work is licensed under a Creative Commons Attribution 4.0 International License. Read Full License 


\section{Abstract}

Background: The relationship between serum carbohydrate antigen 19-9 (CA19-9) and hepatocellular carcinoma (HCC) is unclear. To explore the prognostic value of preoperative CA19-9 in a-fetoprotein (AFP)-positive and -negative HCC with hepatitis B virus (HBV) background (HBV-HCC).

Methods: We evaluated HBV-HCC patients who underwent curative resection (Cohort 1). Recurrence-free survival (RFS) and overall survival (OS) were assessed, and the clinicopathological characteristics were compared according to a CA19-9 cutoff of $\geq 39 \mathrm{U} / \mathrm{ml}$. Immunohistochemical staining of CA19-9 in HCC tumor tissue and background liver were quantified in another cohort of 216 patients with resected HCC (Cohort 2). Immunohistochemical staining or serum CA19-9 level was also compared between patients with intrahepatic cholangiocarcinoma (ICC) (Cohort 3).

Results: In Cohort 1, CA19-9 $\geq 39 \mathrm{U} / \mathrm{ml}$ was an independent risk factor for RFS (HR=1.507, 95\% Cl=1.0872.091, $\mathrm{p}=0.014)$ and OS (HR=1.646, 95\% $\mathrm{Cl}=1.146-2.366, \mathrm{p}=0.007)$ in both AFP-positive and AFP-negative patients. CA19-9 $\geq 39 \mathrm{U} / \mathrm{ml}$ was also associated with significantly higher incidence of macrovascular invasion compared with CA $19-9<39 \mathrm{U} / \mathrm{ml}(23.0 \%$ vs. $7.2 \%, \mathrm{p}=0.002)$, elevated aminotransferase and aspartate aminotransferase to platelet ratio index, and lower albumin. In contrast, no association was found between CA19-9 and systemic inflammation. CA19-9 expression was found exclusively in the background liver but not in HCC tumor cells. In contrast, tumor tissue was the main source of CA19-9 in ICC patients.

Conclusions: CA19-9 $\geq 39 \mathrm{U} / \mathrm{ml}$ was associated with lower OS and RFS in both AFP-positive and negative HCC patients. CA19-9 is secreted by the background liver but not by tumor cells. Thus, CA19-9 is a prognostic marker for liver inflammation and cirrhosis in HCC.

\section{Background}

Primary liver cancer is the sixth most commonly diagnosed cancer and the fourth leading cause of cancer-related death worldwide [1]. In general, primary liver cancer is classified into two types as hepatocellular carcinoma (HCC) and intrahepatic cholangiocarcinoma, with HCC being more common, accounting for $75 \%-85 \%$ of all cases. However, mixed HCC-ICC and other rare types have also been reported. Alpha-fetoprotein (AFP) and carbohydrate antigen $19-9$ (CA19-9) are the most commonly used biomarkers for HCC and ICC. A higher AFP level is associated with poor outcomes after curative resection or liver transplantation [2-4]. CA19-9, also known as sialyl Lewis-a, is mainly used as a biomarker for malignancies of the hepatobiliary tract and pancreas[5]. However, serum CA19-9 levels may also be elevated in gastric, esophageal, and colonic cancers and in a number of non-malignant conditions that are associated with jaundice [6]. The serum CA19-9 level is elevated in approximately $60 \%$ of cholangiocarcinoma patients and in $30 \%$ of HCC patients [7]. It is also frequently elevated in patients with combined HCC-cholangiocarcinoma. Elevated preoperative serum CA19-9 levels have been reported to be associated with worse survival in HCC patients who had undergone resection ( $>27 \mathrm{U} / \mathrm{mL}$ ) or liver 
transplantation (>100 U/ml) [8-10]. However, most of these studies mainly included patients with HCVrelated $\mathrm{HCC}$ who underwent resection or transplantation, and the underlying mechanism by which CA19-9 influences prognosis remains unclear.

Thus, this study aimed to investigate the prognostic value of preoperative serum CA19-9 according to AFP status in HCC patients and in ICC patients with HBV background who underwent curative resection.

\section{Methods}

\section{Patients and study design}

We retrospectively evaluated three patient cohorts as follows. Cohort 1 involved 380 patients diagnosed with HCC at Tianjin Medical University Cancer Institute \& Hospital (Tianjin, People's Republic of China) between 2012 and 2013. In this cohort, CA19-9 (+) was defined as serum CA19-9 $\geq 39 \mathrm{U} / \mathrm{ml}$, whereas CA19-9 (-) was defined as serum CA19-9 $<39 \mathrm{U} / \mathrm{ml}$, according to the upper limit of serum CA19-9 in our hospital. AFP (+) was defined as serum AFP $>20 \mathrm{ng} / \mathrm{ml}$, whereas AFP (-) was AFP $\leq 20 \mathrm{ng} / \mathrm{ml}$. Cohort 2 involved 216 patients with resected HCC in whom tissue microarray (TMA) samples were obtained. Patients with lymph node metastasis or distant metastasis were excluded to reduce the confounding factors. Cohort 3 included 136 ICC patients whose paraffin blocks were collected based on the availability of suitable formalin-fixed, paraffin-embedded tissue and complete clinicopathologic and follow-up data of the patients.

All the patients underwent curative resection for $\mathrm{HCC}$, defined as complete macroscopic removal of the tumor. All tumors were staged according to the TNM classification system of International Union Against Cancer (8th edition) and the Barcelona Clinic Liver Cancer guidelines.

\section{Demographic And Clinicopathological Factors}

Demographic and clinicopathological factors including tumor factors, systemic inflammation factors, and liver factors were evaluated. Demographic factors included sex and age. Tumor factors included tumor size, number of tumor lesions, macroscopic vascular invasion (MaVI), microscopic vascular invasion (MiVI), intrahepatic metastasis, and tumor differentiation according to Edmondson's grade. Systemic factors included the neutrophil-to-lymphocyte ratio (NLR) and platelet-to-lymphocyte ratio (PLR). Liver factors included intraoperative detection of liver cirrhosis; alanine aminotransferase (ALT), aspartate aminotransferase (AST), gamma-glutamyl transpeptidase (rGT), alkaline phosphatase (ALP), total bilirubin, and albumin levels; prothrombin time (PT); and the aspartate aminotransferase-to-platelet ratio index (APRI) as the parameter most closely related to liver cirrhosis and fibrosis in both chronic hepatitis $B[11-13]$ and hepatitis $C[14,15]$. NLR and PLR are both indicators of systemic inflammation and its relationship with the prognosis of several cancers has been identified [16-19]. 


\section{Tma In Icc}

We selected 158 consecutive patients with ICC who underwent surgical treatment at Tianjin Medical University Cancer Institute and Hospital between January 2012 and December 2017. Patients with combined HCC-CCA (i.e., HCC and ICC) were excluded. The specimens of all patients were reviewed by two independent pathologists (Y.B. and Z.F.L.) to confirm the diagnosis of ICC and for restaging according to the 8th edition of the 2017 American Joint Committee on Cancer staging system. Of the 158 patients, we excluded 28 because of loss to follow-up $(n=11)$, non-R0 resection $(n=14)$, death from postoperative complications $(n=1)$, and death from non-tumor-related causes $(n=2)$. Thus, 130 patients (Cohort 3) were eventually included for the comparison of clinical characteristics and survival analyses. The patients' formalin-fixed paraffin-embedded (FFPE) samples and hematoxylin-eosin (HE) staining slides from surgical specimens were then collected from the Pathology Department of Tianjin Medical University Cancer Institute and Hospital. TMA samples comprising 2-mm cores of FFPE tumor tissue were prepared for various staining procedures by selecting representative tumor areas and a typical paratumoral region from each case. The Medical Ethics Committee of Tianjin Medical University Cancer Institute and Hospital approved this study, and informed consent was obtained from all patients or their legal guardian.

\section{Follow-up And Postoperative Treatment}

After surgery, patients were routinely followed. Follow-up was censored on July 10, 2019, with the patients followed up for a median of 56.6 months. All patients were monitored prospectively according to serum AFP and carbohydrate antigen 19 - 9 levels and using abdomen ultrasonography every 2 months in the first year and every 3 months after the first year. Recurrence was confirmed using computed tomography and/or magnetic resonance imaging based on typical imaging appearance in the imaging scan and an elevated AFP level. The treatment modality after relapse varied among individuals.

\section{Tma And Immunohistochemistry}

TMAs were constructed as described previously [20]. TMAs sections were dewaxed and rehydrated in xylene and gradient ethanol, respectively. After antigen retrieval and endogenous peroxidase activity blocking, the slides were incubated with primary antibodies $\left(4^{\circ} \mathrm{C}\right.$ for $14 \mathrm{~h}$ and $37^{\circ} \mathrm{C}$ for $\left.1 \mathrm{~h}\right)$ and HRPconjugated secondary antibody $\left(37^{\circ} \mathrm{C}\right.$ for $\left.1 \mathrm{~h}\right)$ in turn. Then the sections were visualized with $3,3^{\prime}-$ diaminobenzidine (ZLI-9017; Zhongshan Goldbridge) for 5 min and counterstained with Hematoxylin. Appropriate internal or external positive controls and negative controls were designed and used for each round [20]. The primary antibody used in the present study was anti-human CA19-9 (Zhongshan Company). Negative control slides omitting the primary antibodies were included in all assays. CA19-9 immunoreactivity was evaluated in a semiquantitative manner by evaluating both staining intensity and the percentage of immunopositive tumor cells. 


\section{Statistical analysis}

Kaplan-Meier method and Log-rank test with survival curves were used in univariate analyses of cumulative survival. Multivariate analyses were based on the Cox proportional hazards regression model. For the comparison of individual variables, $\chi^{2}$ tests and Student's t-tests were used as appropriate. All statistical analyses were performed using SPSS software (SPSS v22.0, Chicago, IL). A two-tailed $P$ value of $<0.05$ was considered statistically significant.

\section{Results}

\section{CA19-9 was an independent risk factor for RFS and OS}

In Cohort 1, the 1-, 3-, and 5-year overall survival (OS) rates for CA19-9 (+) patients were $80.3 \%, 37.7 \%$, and $34.4 \%$, respectively, and were $90.3 \%, 62.7 \%$, and $51.4 \%$, respectively, for the CA19-9 (-) patients (Fig. $1 \mathrm{a}$ ). The 1-, 3-, and 5-year RFS rates for the CA19-9 (+) patients were $45.9 \%, 14.8 \%$, and $13.1 \%$, respectively, and were $67.1 \%, 40.4 \%$, and 33.5\%, respectively, for the CA19-9 (-) patients (Fig. 1b). The 1-, 3-, and 5-year OS rates for AFP (+) patients were $84.0 \%, 47.1 \%$, and $38.3 \%$, respectively, and were $94.2 \%, 72.4 \%$, and $60.9 \%$, respectively, for the AFP (-) patients (Fig. 1c). The 1-, 3-, and 5-year RFS for the AFP (+) patients were $54.9 \%, 29.1 \%$, and $24.8 \%$, respectively, and were $74.7 \%, 44.8 \%$, and $37.4 \%$, respectively, for the AFP (-) patients (Fig. 1d).

In multivariate analysis, tumor size $>5 \mathrm{~cm}$, presence of $\mathrm{MaVl}, \mathrm{AFP}>20 \mathrm{ng} / \mathrm{ml}$, and CA19-9 $\geq 39 \mathrm{U} / \mathrm{ml}$ were independent risk factors for RFS. Meanwhile, tumor size $>5 \mathrm{~cm}$, presence of MaVl, AFP $>20 \mathrm{ng} / \mathrm{ml}$, CA19$9 \geq 39 \mathrm{U} / \mathrm{ml}$, and albumin $\leq 35 \mathrm{~g} / \mathrm{L}$ were independent risk factors for OS (Tables 1 and 2). 
Table 1

Univariate and multivariate analysis for RFS in Cohort 1.

\begin{tabular}{|c|c|c|c|c|}
\hline \multirow{3}{*}{$\begin{array}{l}\text { Recurrence-free Survival } \\
\text { Variable }\end{array}$} & \multirow[t]{3}{*}{ Comparison } & \multirow{3}{*}{$\begin{array}{l}\text { Univariate } \\
\text { P-value }\end{array}$} & \multicolumn{2}{|c|}{ Multivariate } \\
\hline & & & \multirow[t]{2}{*}{ P-value } & \multirow{2}{*}{$\begin{array}{l}\text { Hazard Ratio } \\
(95.0 \% \mathrm{Cl})\end{array}$} \\
\hline & & & & \\
\hline Gender & Male vs. female & 0.268 & & \\
\hline Age & $\leq 50$ vs. $>50$ years & 0.957 & & \\
\hline Tumor size & $\leq 5$ vs. $>5 \mathrm{~cm}$ & $<0.001$ & 0.001 & $1.569(1.204-2.045)$ \\
\hline number & Solitary vs. multiple & 0.075 & & \\
\hline MaVI & Yes vs. no & $<0.001$ & 0.023 & $1.586(1.065-2.361)$ \\
\hline Differentiation & I/II/III/IV & 0.482 & & \\
\hline MiVI & Yes vs. no & 0.025 & & \\
\hline IHM & Yes vs. no & 0.022 & & \\
\hline Cirrhosis & Yes vs. no & 0.588 & & \\
\hline $\mathrm{HBeAg}$ & Yes vs. no & 0.142 & & \\
\hline PT & $\leq 11$ vs. $>11$ seconds & 0.338 & & \\
\hline AFP & $\leq 20$ vs. $>20 \mathrm{ng} / \mathrm{mL}$ & $<0.001$ & 0.012 & $1.373(1.071-1.759)$ \\
\hline CA19-9 & $\geq 39 \mathrm{vs} .<39 \mathrm{U} / \mathrm{ml}$ & $<0.001$ & 0.014 & $1.507(1.087-2.091)$ \\
\hline ALT & $\leq 40$ vs. $>40 \mathrm{U} / \mathrm{L}$ & 0.046 & & \\
\hline AST & $\leq 40$ vs. $>40 \mathrm{U} / \mathrm{L}$ & $<0.001$ & & \\
\hline Albumin & $\leq 35$ vs. $>35 \mathrm{~g} / \mathrm{L}$ & 0.114 & & \\
\hline NLR & $\leq 5$ vs. $>5$ & 0.019 & & \\
\hline PLR & $\leq 300$ vs. $>300$ & 0.072 & & \\
\hline TB & $\leq 19$ vs. $>19 \mu \mathrm{mol} / \mathrm{L}$ & 0.975 & & \\
\hline ALP & $\leq 130$ vs. $>130$ & 0.210 & & \\
\hline rGT & $\leq 60$ vs. $>60 \mathrm{U} / \mathrm{L}$ & $<0.001$ & & \\
\hline HKLC & $0 / 1 / 2 / 3$ & $<0.001$ & NA & \\
\hline BCLC & $\mathrm{A} / \mathrm{B} / \mathrm{C}$ & $<0.001$ & NA & \\
\hline \multicolumn{5}{|c|}{ Note: MaVI, Macroscopic Vascular Invasion. } \\
\hline MiVI, Micros & Invasion. & & & \\
\hline
\end{tabular}




\begin{tabular}{|lll|}
\hline Recurrence-free Survival Comparison & Univariate & Multivariate \\
\cline { 2 - 3 } Variable & P-value & P-value Hazard Ratio \\
& & $(95.0 \% \mathbf{C l})$ \\
\hline IHM, Intrahepatic Metastasis. & \\
\hline HBeAg, Hepatitis B virus e Antigen. & \\
\hline PT, Prothrombin Time. & \\
\hline AFP, a-fetoprotein. \\
\hline CA19-9, Carbohydrate Antigen 19-9. \\
\hline ALT, Alanine Aminotransferase. \\
\hline AST, Aspartate Aminotransferase. \\
\hline ALP, Alkaline Phosphatase. \\
\hline rGT, Gamma-glutamyl Transpeptidase. \\
\hline TB, Total Bilirubin. \\
\hline APRI, Aspartate aminotransferase to Platelet Ratio Index. \\
\hline NLR, Neutrophil-to-Lymphocyte Ratio. \\
\hline PLR, Platelet-to-Lymphocyte Ratio. \\
\hline NA, Not Applicable. \\
\hline
\end{tabular}


Table 2

Univariate and multivariate analysis for OS in Cohort 1.

\begin{tabular}{|c|c|c|c|c|}
\hline \multirow{3}{*}{$\begin{array}{l}\text { Overall Survival } \\
\text { Variable }\end{array}$} & \multirow[t]{3}{*}{ Comparison } & \multirow{3}{*}{$\begin{array}{l}\text { Univariate } \\
\text { P-value }\end{array}$} & \multicolumn{2}{|c|}{ Multivariate } \\
\hline & & & \multirow[t]{2}{*}{ P-value } & \multirow{2}{*}{$\begin{array}{l}\text { Hazard Ratio } \\
(95.0 \% \mathrm{Cl})\end{array}$} \\
\hline & & & & \\
\hline Gender & Male vs. female & 0.222 & & \\
\hline Age & $\leq 50$ vs. $>50$ years & 0.246 & & \\
\hline Tumor size & $\leq 5 \mathrm{vs} .>5 \mathrm{~cm}$ & $<0.001$ & $<0.001$ & $1.931(1.430-2.607)$ \\
\hline Number & Solitary vs. multiple & 0.029 & & \\
\hline MaVI & Yes vs. no & $<0.001$ & 0.003 & $1.871(1.230-2.847)$ \\
\hline Differentiation & I/II/III/IV & 0.216 & & \\
\hline MiVI & Yes vs. no & $<0.001$ & & \\
\hline $\mathrm{IHM}$ & Yes vs. no & 0.002 & 0.009 & $1.483(1.104-1.992)$ \\
\hline Cirrhosis & Yes vs. no & 0.158 & & \\
\hline $\mathrm{HBeAg}$ & Yes vs. no & 0.798 & & \\
\hline PT & $\leq 11$ vs. $>11$ seconds & 0.615 & & \\
\hline AFP & $\leq 20 \mathrm{vs} .>20 \mathrm{ng} / \mathrm{mL}$ & $<0.001$ & 0.003 & $1.558(1.163-2.089)$ \\
\hline CA19-9 & $\geq 39$ vs. $<39 \mathrm{U} / \mathrm{ml}$ & 0.001 & 0.007 & $1.646(1.146-2.366)$ \\
\hline ALT & $\leq 40$ vs. $>40 \mathrm{U} / \mathrm{L}$ & 0.142 & & \\
\hline AST & $\leq 40$ vs. $>40 \mathrm{U} / \mathrm{L}$ & $<0.001$ & & \\
\hline NLR & $\leq 5$ vs. $>5$ & $<0.001$ & & \\
\hline PLR & $\leq 300$ vs. $>300$ & 0.004 & 0.029 & $2.920(1.118-7.624)$ \\
\hline ALP & $\leq 130$ vs. $>30$ & 0.026 & & \\
\hline Albumin & $\leq 35$ vs. $>35 \mathrm{~g} / \mathrm{L}$ & 0.174 & & \\
\hline rGT & $\leq 60$ vs. $>60 \mathrm{U} / \mathrm{L}$ & $<0.001$ & & \\
\hline TB & $\leq 19$ vs. $>19 \mu \mathrm{mol} / \mathrm{L}$ & 0.056 & & \\
\hline HKLC & $0 / 1 / 2 / 3$ & 0.011 & NA & \\
\hline BCLC & $\mathrm{A} / \mathrm{B} / \mathrm{C}$ & $<0.001$ & NA & \\
\hline \multicolumn{5}{|c|}{ Note: MaVI, Macroscopic Vascular Invasion. } \\
\hline MiVl, Micr & ascular Invasion. & & & \\
\hline
\end{tabular}




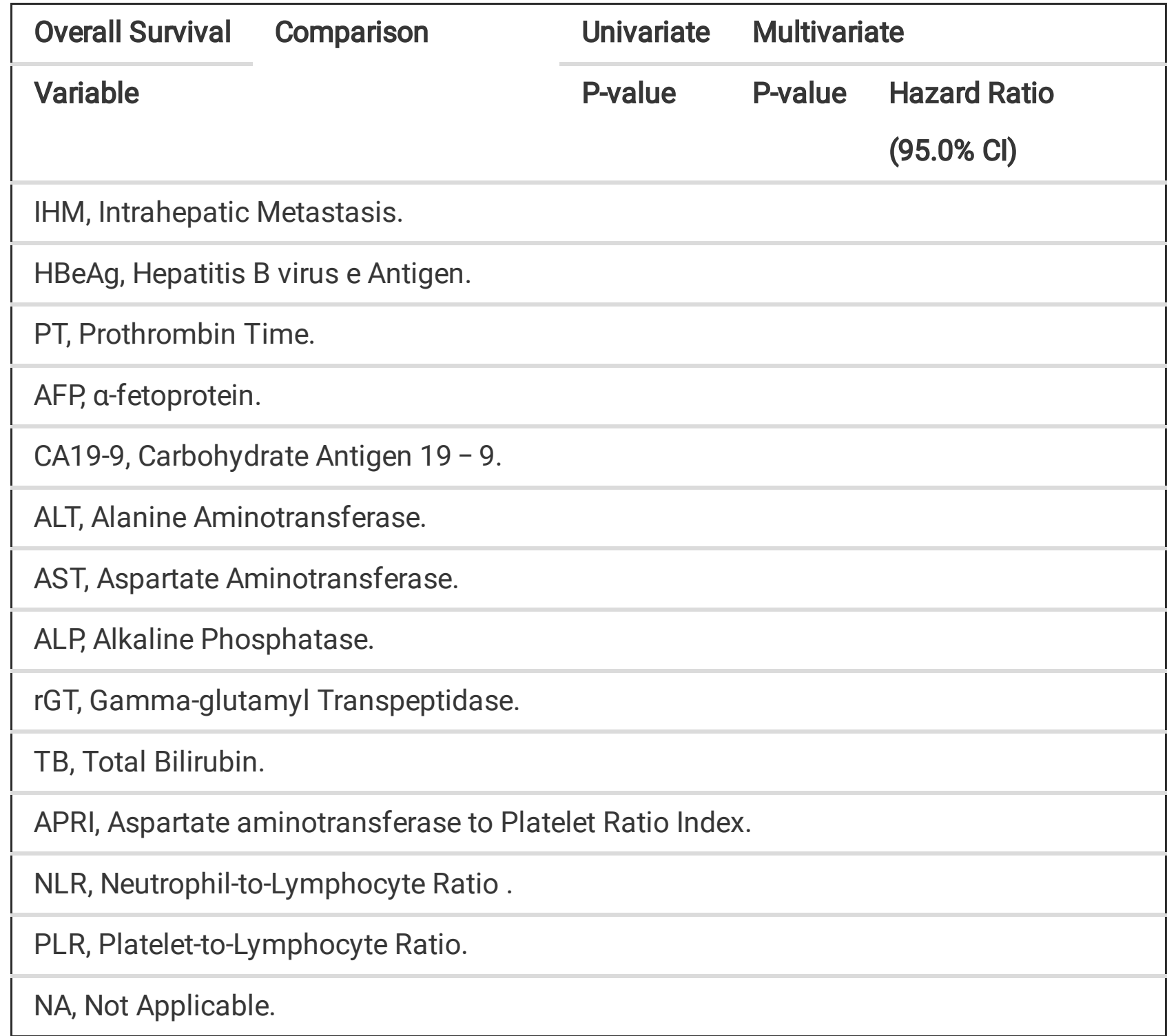

\section{Positive CA19-9 predicted worse prognosis in both AFP (+) and AFP (-) HCC patients}

The 1-, 3-, and 5-year OS for patients with CA19-9 (-) and AFP (-) were 95.4\%, 74.5\%, 61.4\%, respectively, whereas they were $83.3 \%, 50.0 \%$, and $45.8 \%$, respectively, for patients with CA19-9 $(+)$ and AFP $(-)(\mathrm{p}<$ 0.05, Fig. 1e). The 1-, 3-, and 5-year RFS for patients with CA19-9 (-) and AFP (-) were $77.1 \%, 47.1 \%$, and $39.2 \%$, respectively, whereas they were $45.8 \%, 20.8 \%$, and $16.7 \%$, respectively, in CA19-9 (+) and AFP (-) patients $(p<0.05$, Fig. 1f). These results showed that CA19-9 (+) predicted worse OS and RFS in AFP (-) patients.

The 1-, 3-, and 5-year OS for patients with CA19-9 (-) and AFP (+) were 84.7\%, 52.8\%, and $42.9 \%$, respectively, and were $77.5 \%, 27.5 \%$, and $22.5 \%$, respectively, for patients with CA19-9 $(+)$ and AFP $(+)(\mathrm{p}<$ 0.05, Fig. 1e). The 1-, 3-, and 5-year RFS for patients with CA19-9 (-) and AFP (+) were $58.9 \%, 34.4 \%$, and $28.8 \%$, respectively ( $p<0.05$, Fig. $1 f)$, whereas they were $40.0 \%, 10.0 \%$, and $7.5 \%$, respectively, for patients with CA19-9 $(+)$ and AFP $(+)(p<0.05$, Fig. 1f). These results indicate that CA19-9 $(+)$ predicted worse OS 
and RFS in AFP (+) patients. In summary, CA19-9 (+) predicted worse OS and RFS in both AFP (+) and AFP (-) HCC patients.

\section{CA19-9 was associated with higher incidence of $\mathrm{MaVl}$ and a trend toward multiple tumors}

CA19-9 was not associated with tumor size $(6.1 \pm 4.8 \mathrm{~cm}$ vs. $5.6 \pm 3.8 \mathrm{~cm}, \mathrm{p}=0.404)$, MiVI $(62.3 \%$ vs. $54.9 \%, p=0.225)$ and AFP (5488.9 $\pm 28616.1 \mathrm{ng} / \mathrm{ml}$ vs. $5401.4 \pm 40162.5 \mathrm{ng} / \mathrm{ml}, \mathrm{p}=0.987)$. However, CA19-9 was related to higher incidence of $\mathrm{MaVI}(23.0 \%$ vs. $7.2 \%, \mathrm{p}=0.002)$, and a trend toward more multiple tumors with marginal significance $(23.0 \%$ vs. $13.8 \%, p=0.068)$ (Table 3 ). 
Table 3

Comparison of clinicopathological factors between patients with CA19-9 (+) and CA19-9 (-).

\begin{tabular}{|c|c|c|c|}
\hline Cohort 1. Variable & $\begin{array}{l}\text { CA } 19-9<39 \mathrm{U} / \mathrm{ml} \\
(\mathrm{n}=319)\end{array}$ & $\begin{array}{l}\mathrm{CA} 19-9 \geq 39 \mathrm{U} / \mathrm{ml} \\
(\mathrm{n}=61)\end{array}$ & P-value \\
\hline Gender (Male/Female) & $255 / 64(78.0 \%)$ & $48 / 13(78.7 \%)$ & 0.824 \\
\hline Age (year) (Mean \pm SD) & $55.4 \pm 10.6$ & $58.4 \pm 10.4$ & 0.048 \\
\hline Tumor size (Mean \pm SD) & $5.6 \pm 3.8$ & $6.1 \pm 4.8$ & 0.404 \\
\hline Number (Solitary vs. multiple) & $275 / 44(13.8 \%)$ & $47 / 14(23.0 \%)$ & 0.068 \\
\hline MaVI (Yes vs. no) & $23 / 296(7.2 \%)$ & $12 / 49(23.0 \%)$ & 0.002 \\
\hline MiVI (Yes vs. no) & $175 / 144(54.9 \%)$ & $38 / 22(62.3 \%)$ & 0.225 \\
\hline IHM (Yes vs. no) & $111 / 208(34.8 \%)$ & 24/36 (39.3\%) & 0.440 \\
\hline AFP $(n g / m L)($ Mean $\pm S D)$ & $5401.4 \pm 40162.5$ & $5488.9 \pm 28616.1$ & 0.987 \\
\hline HBeAg(Yes vs. no) & $45 / 274$ & $12 / 49$ & 0.265 \\
\hline Cirrhosis (Yes vs. no) & $179 / 140(56.1 \%)$ & $43 / 18(70.5 \%)$ & 0.037 \\
\hline APRI (Mean \pm SD) & $0.72 \pm 0.96$ & $1.53 \pm 1.61$ & $P<0.001$ \\
\hline Ascites (Yes vs. no) & $32 / 287$ & $7 / 54$ & 0.733 \\
\hline rGT (Mean \pm SD) & $81.4 \pm 99.4$ & $147.1 \pm 162.4$ & 0.003 \\
\hline ALP (Mean \pm SD) & $95.7 \pm 52.9$ & $117.5 \pm 70.2$ & 0.006 \\
\hline ALT (U/L) (Mean \pm SD) & $43.9 \pm 59.5$ & $75.4 \pm 77.3$ & 0.004 \\
\hline AST (U/L) (Mean \pm SD) & $41.5 \pm 46.0$ & $75.1 \pm 69.0$ & $<0.001$ \\
\hline PT (seconds) (Mean \pm SD) & $11.3 \pm 1.2$ & $12.1 \pm 1.0$ & $<0.001$ \\
\hline Albumin $(\mathrm{g} / \mathrm{L})($ Mean $\pm \mathrm{SD})$ & $42.0 \pm 5.3$ & $39.8 \pm 5.5$ & 0.002 \\
\hline TB $(\mu \mathrm{mol} / \mathrm{L})($ Mean \pm SD $)$ & $18.5 \pm 9.8$ & $26.4 \pm 37.8$ & 0.109 \\
\hline NLR (Mean \pm SD) & $2.3 \pm 1.5$ & $2.1 \pm 1.4$ & 0.388 \\
\hline PLR (Mean \pm SD) & $134.3 \pm 368.7$ & $95.5 \pm 47.8$ & 0.412 \\
\hline
\end{tabular}

\section{CA19-9 was associated with more severe liver cirrhosis and liver inflammation but not with systemic inflammation}


Comparison of clinicopathological factors between CA19-9 (+) and CA19-9(-) patients revealed that CA19$9(+)$ patients tend to be older (mean age: $58.4 \pm 10.4$ years vs. $55.4 \pm 10.6$ years, $p=0.048$ ), have higher incidence of liver cirrhosis (70.5\% vs. $56.1 \%, p=0.037)$, higher APRI ( $1.53 \pm 1.61$ vs. $0.72 \pm 0.96, p<0.001)$, longer PT (12.1 \pm 1.0 vs. $11.3 \pm 1.2, p<0.001)$, elevated ALT $(75.4 \pm 77.3 \mathrm{U} / \mathrm{L}$ vs. $43.9 \pm 59.5 \mathrm{U} / \mathrm{L}, \mathrm{p}=$ $0.004)$, elevated AST $(75.1 \pm 69.0 \mathrm{U} / \mathrm{L}$ vs. $41.5 \pm 46.0 \mathrm{U} / \mathrm{L}, \mathrm{p}<0.001)$, increased $\mathrm{rGT}(147.1 \pm 162.4 \mathrm{U} / \mathrm{L}$ vs. $81.4 \pm 99.4 \mathrm{U} / \mathrm{L}, \mathrm{P}=0.003)$, higher level of $\operatorname{ALP}(117.5 \pm 70.2 \mathrm{ng} / \mathrm{ml}$ vs. $95.7 \pm 52.9 \mathrm{ng} / \mathrm{ml}, p=0.006)$, and lower level of albumin $(39.8 \pm 5.5 \mathrm{~g} / \mathrm{L}$ vs. $42.0 \pm 5.3 \mathrm{~g} / \mathrm{L}, \mathrm{p}=0.002)$ (Table 3$)$. All the factors except MaVI are related to liver cirrhosis.

To exclude the confounding effect of MaVI, we excluded patients with MaVI. The results showed that CA19-9 was still correlated with liver cirrhosis, APRI, ALT, AST, rGT, ALP, and albumin (data not shown). Furthermore, multivariate analysis showed that CA19-9 (+) and MaVI (+) were both independent risk factors for RFS.

In the current study, CA19-9 was not correlated to NLR or PLR, indicating that CA19-9 was not correlated to systemic inflammation.

\section{Immunohistochemical staining}

To determine the source of CA19-9, we examined its expression in TMA samples of HCC patients. Immunohistochemical staining of CA19-9 in both tumor tissue and non-tumor liver parenchyma specimens from HCC patients was also assessed. The results showed that none of the HCC tumor cells express CA19-9, and CA19-9 was expressed in non-tumor liver parenchyma in all patients.

Immunohistochemical staining of CA19-9 in both tumor and non-tumor liver parenchyma samples from Cohort 3 revealed that CA19-9 was expressed in 64\% (87/136) of ICC tumors and 4.4\% (6/136) of nontumor liver parenchyma. Serum CA19-9 was positive $(\geq 39 \mathrm{U} / \mathrm{ml})$ in $58.1 \%$ and negative $(<39 \mathrm{U} / \mathrm{ml})$ in $41.9 \%$ of the patients with ICC. The results that immunohistochemical staining of CA19-9 was positive only in $4.4 \%$ of ICCs indicate that serum CA19-9 mainly derives from the tumor tissue of patients with ICC, which is distinct from the dominant expression of CA19-9 in the background liver in HCC patients.

\section{Discussion}

In the current study, it is revealed that CA19-9 is associated with lower OS and RFS in both AFP (+) and AFP (-) patients. CA19-9 is associated with higher incidence of macrovascular invasion and more severe liver cirrhosis and inflammation. Importantly, immunostaining of CA19-9 showed that it is secreted by the background liver, but not by tumor cells in patients with HCC.

CA19-9 is generally recognized as a tumor marker for gastrointestinal and especially hepatobiliary cancers [21], however, CA19-9 is frequently elevated in biliary obstruction [22]. In hepatocellular carcinoma, CA19-9 elevation may stand for a subgroup of patients with partial cholangiocytic differentiation [23]. However, the significance of CA19-9 in pure HCC is still far from clear. In the current study, we excluded mixed HCC-ICC as well as cholangiocytic differentiation by two independent 
pathologists, and immunohistochemical staining of CA19-9 in HCC and ICC tumor tissues as well as nontumor liver parenchyma confirmed that CA19-9 is secreted exclusively by the background liver but not by tumor cells in patients with HCC. In contrast, CA19-9 was frequently expressed in ICC tumors $(64 \%, n=$ $87 / 136)$, but rarely in the non-tumor liver parenchyma $(4.4 \%, 6 / 136)$.

In Cohorts 1 and 2, CA19-9 $\geq 39 \mathrm{U} / \mathrm{ml}$ was associated with a high incidence of MaVl, elevated rGT, ALT, AST, PT, and APRI; and decreased albumin. Furthermore, there were no significant difference in NLR and PLR, as biomarkers of systemic inflammation, between CA19-9 (+) and CA19-9 (-) patients, indicating that CA19-9 is not associated with systemic inflammation. Previous reports have shown that elevated ALT, AST, and rGT levels are correlated to liver fibrosis, cirrhosis [24, 25], and recurrence [26, 27]. Thus, we confirmed that CA19-9 is a liver biomarker that higher serum CA19-9 level indicated more severe liver inflammation and liver cirrhosis rather than a tumor factor in HCC.

Macrovascular invasion and multiple tumor nodules were more common in CA19-9 (+) patients. These findings can be attributed to two reasons. First, chronic inflammatory diseases are the key etiological risk factors for HCC [28], and an elevated ALT/AST/APRI in patients with elevated CA19-9 indicated more severe liver cirrhosis and an inflamed liver background [29,30], which is closely related to de novo tumor pathogenesis and multicentric recurrence [31, 32]. Second, liver inflammation may promote intravenous metastasis of HCC tumor cells and has been reported as an independent risk factor for early tumor recurrence in patients with $\mathrm{HCC}$ [33-35].

Persistently elevated CA19-9 levels had been reported to predict poor prognosis in HCC. Chen et al. [9] found that $34.9 \%(106 / 304)$ of patients with HBV- and HCV-related HCC have CA19-9 levels $>27 \mathrm{U} / \mathrm{ml}$. Further, a preoperative CA19-9 value of $>27 \mathrm{U} / \mathrm{mL}$ was associated with poor prognosis after resection for HCC. However, the authors did not compare the clinicopathological factors related to liver inflammation and liver cirrhosis (e.g., ALT, AST, ALP, rGT, and albumin) according to a CA19-9 cutoff of $\leq 27 \mathrm{U} / \mathrm{mL}$. Wan et al. [10] also showed that preoperative serum AFP levels of $>400 \mathrm{ng} / \mathrm{ml}$ and CA19-9 $>100 \mathrm{U} / \mathrm{ml}$ predicted survival after liver transplantation in patients with HCC. However, the study only included patients with liver transplantation and did not exclude patients with ICC or CHCC-CC. Hsu et al. [8] investigated 145 cases of HCV-related HCC and found that an elevated serum CA19-9 level of $\geq 100 \mathrm{U} / \mathrm{ml}$ is an independent predictor of poor OS. However, $59 \%$ (85/145) of the HCC patients had underlying hepatitis $C$ virus, and only $16 \%$ had hepatitis $B$ virus. Lu et al. [36] evaluated 750 cases of AFP-negative $\mathrm{HCC}$ and found that a preoperative CA19-9 level of $>32.6 \mathrm{U} / \mathrm{ml}$ predicted poor prognosis and can thus be used as a prognostic marker in AFP-negative HCC.

The current study is the only study including purely patients with HBV-related HCC. At a cut-off value of $39 \mathrm{U} / \mathrm{mL}, 16.1 \%$ of patients $(61 / 380)$ were found to be CA19-9 positive, and CA19-9 $\geq 39 \mathrm{U} / \mathrm{ml}$ predicted worse OS and RFS in both AFP(-) and AFP (+) patients. These findings indicate that patients with CA19-9 $\geq 39 \mathrm{U} / \mathrm{ml}$ should be closely followed up considering the higher incidence of tumor recurrence and mortality rate caused by more severe liver cirrhosis and inflammation in this population. Antiinflammatory medications may be helpful in reducing the risk of tumor recurrence. 
Our study has several limitations. First, it is a single-center study of retrospective cohorts, and only the serum level and immunohistochemical expression of CA19-9 were evaluated. Second, the precise mechanism by which CA19-9 promotes macroscopic vascular invasion is still unclear and thus further studies are needed to elucidate the underlying mechanism.

\section{Conclusions}

In conclusion, CA19-9 is associated with lower OS and RFS in both AFP (+) and AFP (-) patients. Importantly, CA19-9 is secreted by the background liver, but not by tumor cells in patients with HCC. Thus, CA19-9 is not a tumor biomarker, but a biomarker for liver cirrhosis and inflammation and a risk factor for worse OS and RFS in HCC.

\section{Abbreviations}

AFP, a-fetoprotein.

ALP, Alkaline Phosphatase.

ALT, Alanine Aminotransferase.

APRI, Aspartate aminotransferase to Platelet Ratio Index.

AST, Aspartate Aminotransferase.

CA19-9, Carbohydrate Antigen 19-9.

HBeAg, Hepatitis B virus e Antigen.

HCC, Hepatocellular carcinoma

ICC, Intrahepatic cholangiocarcinoma

IHM, Intrahepatic Metastasis.

MaVI, Macroscopic Vascular Invasion.

MiVI, Microscopic Vascular Invasion.

NA, Not Applicable.

NLR, Neutrophil-to-Lymphocyte Ratio .

PLR, Platelet-to-Lymphocyte Ratio.

PT, Prothrombin Time. 
rGT, Gamma-glutamyl Transpeptidase.

TB, Total Bilirubin.

\section{Declarations}

\section{Ethics approval and consent to participate}

Informed consent was obtained from the patient for publication of their information.

\section{Consent to publish}

All authors agree to publish the article in BMC Gastroenterology.

\section{Availability of data and materials}

All data for non-commercial profit purposes can be obtained from the corresponding author.

\section{Competing interests}

The authors declare that they have no competing interests.

\section{Funding}

This research was supported by funds as follows.

(a) National Natural Science Foundation of China, No. 81572434. (Provide the reagent for immunohistochemistry staining of CA19-9)

(b) Ministry of Science and Technology, National Science and Technology Major Special Project: Prevention and Treatment of Major Infectious Diseases such as AIDS and Viral Hepatitis, 2018ZX10723204-007-001. (Provide the lab resource)

(c) "Young Medical Elites," Tianjin Health Commission, No.2018-2-8. (Provide the reagent for immunohistochemistry staining of CA19-9)

(d) "Young Innovative Talents," Tianjin Medical University Cancer Institute and Hospital, No.2017-1-35. (Provide the reagent for immunohistochemistry staining of CA19-9)

\section{Authors' Contributions}

ZW conceived the study concept and design and drafted the manuscript.

WYY, YB, CL, ZZW, CGT, HXY, LGH performed the acquisition of data and critical revision of the manuscript for important intellectual content. LHK, CYL, WQ, ZT, STQ and LQ assisted in clinical data and follow-up. All authors have read and approved the final manuscript. 
Acknowledgements

The authors would like to thank Dr. Sun Tao from Nankai University for discussion of the manuscript.

\section{Publisher's Note}

Wei Zhang, Ying-Ying Wang, and Bo Yang should be regarded as co-first authors.

\section{References}

1. Bray F, Ferlay J, Soerjomataram I, Siegel RL, Torre LA, Jemal A. Global cancer statistics 2018 : GLOBOCAN estimates of incidence and mortality worldwide for 36 cancers in 185 countries. CA Cancer J Clin. 2018;68:394-424.

2. Duvoux C, Roudot-Thoraval F, Decaens T, Pessione F, Badran H, Piardi T, et al. Liver transplantation for hepatocellular carcinoma: a model including alpha-fetoprotein improves the performance of Milan criteria. Gastroenterology. 2012;143:986-94 e3;quiz e14-5.

3. Borzio M, Dionigi E, Rossini A, Marignani M, Sacco R, De Sio I, et al. External validation of the ITA.LI.CA prognostic system for patients with hepatocellular carcinoma: A multicenter cohort study. Hepatology. 2018;67:2215-2225.

4. Hameed B, Mehta N, Sapisochin G, Roberts JP, Yao FY. Alpha-fetoprotein level $>1000 \mathrm{ng} / \mathrm{mL}$ as an exclusion criterion for liver transplantation in patients with hepatocellular carcinoma meeting the Milan criteria. Liver Transpl. 2014;20:945-51.

5. Singh S, Tang SJ, Sreenarasimhaiah J, Lara LF, Siddiqui A. The clinical utility and limitations of serum carbohydrate antigen (CA19-9) as a diagnostic tool for pancreatic cancer and cholangiocarcinoma. Dig Dis Sci. 2011;56:2491-6.

6. Marrelli D, Caruso S, Pedrazzani C, Neri A, Fernandes E, Marini M, et al. CA19-9 serum levels in obstructive jaundice: clinical value in benign and malignant conditions. Am J Surg. 2009;198:333-9.

7. Tsuji M, Kashihara T, Terada N, Mori H. An immunohistochemical study of hepatic atypical adenomatous hyperplasia, hepatocellular carcinoma, and cholangiocarcinoma with alphafetoprotein, carcinoembryonic antigen, CA19-9, epithelial membrane antigen, and cytokeratins 18 and 19. Pathol Int. 1999;49:310-7.

8. Hsu CC, Goyal A, luga A, Krishnamoorthy S, Lee V, Verna EC, et al. Elevated CA19-9 Is Associated With Increased Mortality In A Prospective Cohort Of Hepatocellular Carcinoma Patients. Clin Transl Gastroenterol. 2015;6:e74.

9. Chen $\mathrm{YL}$, Chen $\mathrm{CH}, \mathrm{Hu} \mathrm{RH}, \mathrm{Ho} \mathrm{MC}$, Jeng YM. Elevated preoperative serum CA19-9 levels in patients with hepatocellular carcinoma is associated with poor prognosis after resection. ScientificWorldJournal. 2013;2013:380797.

10. Wan P, Zhang J, Long X, Li Q, Xu N, Zhang M, et al. Serum levels of preoperative alpha-fetoprotein and CA19-9 predict survival of hepatic carcinoma patients after liver transplantation. Eur $\mathrm{J}$ Gastroenterol Hepatol. 2014;26:553-61. 
11. Lebensztejn DM, Skiba E, Sobaniec-Lotowska M, Kaczmarski M. A simple noninvasive index (APRI) predicts advanced liver fibrosis in children with chronic hepatitis B. Hepatology. 2005;41:1434-5.

12. Shin WG, Park SH, Jang MK, Hahn TH, Kim JB, Lee MS, et al. Aspartate aminotransferase to platelet ratio index (APRI) can predict liver fibrosis in chronic hepatitis B. Dig Liver Dis. 2008;40:267-74.

13. Shen SL, Fu SJ, Chen B, Kuang M, Li SQ, Hua YP, et al. Preoperative aspartate aminotransferase to platelet ratio is an independent prognostic factor for hepatitis B-induced hepatocellular carcinoma after hepatic resection. Ann Surg Oncol. 2014;21:3802-9.

14. Snyder N, Gajula L, Xiao SY, Grady J, Luxon B, Lau DT, et al. APRI: an easy and validated predictor of hepatic fibrosis in chronic hepatitis C. J Clin Gastroenterol. 2006;40:535-42.

15. Castera L, Vergniol J, Foucher J, Le Bail B, Chanteloup E, Haaser M, et al. Prospective comparison of transient elastography, Fibrotest, APRI, and liver biopsy for the assessment of fibrosis in chronic hepatitis C. Gastroenterology. 2005;128:343-50.

16. Amaral SR, Casal Moura M, Carvalho J, Chaves A, Jesus E, Sousa G. Prognostic significance of neutrophil-to-lymphocyte ratio (NLR) and platelet-to-lymphocyte ratio (PLR) in non-small cell lung cancer (NSCLC) treated with immune checkpoint inhibitors. Ann Oncol. 2019;30 Suppl 1:i3.

17. Russo A, Russano M, Franchina T, Migliorino MR, Aprile G, Mansueto G, et al. Neutrophil-toLymphocyte Ratio (NLR), Platelet-to-Lymphocyte Ratio (PLR), and Outcomes with Nivolumab in Pretreated Non-Small Cell Lung Cancer (NSCLC): A Large Retrospective Multicenter Study. Adv Ther. 2020;37:1145-1155.

18. Ryu MH, Kim JH, Oh SC, Park S, Kim JG, Kim JW, et al. Neutrophil-lymphocyte ratio (NLR) as an important prognostic factor for paclitaxel as a second line chemotherapy in advanced gastric cancer (AGC): Results from phase III DREAM study. Ann Oncol. 2018;29 Suppl 8:viii232.

19. Tanaka H, Tamura T, Toyokawa T, Muguruma K, Miki Y, Kubo N, et al. Clinical Relevance of Postoperative Neutrophil-Lymphocyte Ratio (NLR) to Recurrence After Adjuvant Chemotherapy of S-1 for Gastric Cancer. Anticancer Res. 2018;38:3745-3751.

20. Ma B, Meng H, Tian Y, Wang Y, Song T, Zhang T, et al. Distinct clinical and prognostic implication of IDH1/2 mutation and other most frequent mutations in large duct and small duct subtypes of intrahepatic cholangiocarcinoma. BMC Cancer. 2020;20:318.

21. Yuan RH, Jeng YM, Hu RH, Lai PL, Lee PH, Cheng CC, et al. Role of p53 and beta-catenin mutations in conjunction with CK19 expression on early tumor recurrence and prognosis of hepatocellular carcinoma. J Gastrointest Surg. 2011;15:321-329.

22. Strom BL, Iliopoulos D, Atkinson B, Herlyn M, West SL, Maislin G, et al. Pathophysiology of tumor progression in human gallbladder: flow cytometry, CEA, and CA 19-9 levels in bile and serum in different stages of gallbladder disease. J Natl Cancer Inst. 1989;81:1575-1580.

23. Lu XY, Xi T, Lau WY, Dong H, Zhu Z, Shen F, et al. Hepatocellular carcinoma expressing cholangiocyte phenotype is a novel subtype with highly aggressive behavior. Ann Surg Oncol. 2011;18:2210-2217.

24. Li Q, Lu C, Li W, Huang Y, Chen L. The gamma-glutamyl transpeptidase-to-albumin ratio predicts significant fibrosis and cirrhosis in chronic hepatitis B patients. J Viral Hepat. 2017;24:1143-1150. 
25. Lemoine M, Shimakawa Y, Nayagam S, Khalil M, Suso P, Lloyd J, et al. The gamma-glutamyl transpeptidase to platelet ratio (GPR) predicts significant liver fibrosis and cirrhosis in patients with chronic HBV infection in West Africa. Gut. 2016;65:1369-1376.

26. Cheung YS, Chan HL, Wong J, Lee KF, Poon TC, Wong N, et al. Elevated perioperative transaminase level predicts intrahepatic recurrence in hepatitis B-related hepatocellular carcinoma after curative hepatectomy. Asian J Surg. 2008;31:41-49.

27. Zhou L, Wang SB, Chen SG, Qu Q, Rui JA. Prognostic Value of ALT, AST, and AAR in Hepatocellular Carcinoma with B-Type Hepatitis-Associated Cirrhosis after Radical Hepatectomy. Clin Lab. 2018;64:1739-1747.

28. Jiang K, Centeno BA. Primary Liver Cancers, Part 2: Progression Pathways and Carcinogenesis. Cancer Control. 2018;25:1073274817744658.

29. Tarao K, Rino Y, Takemiya S, Tamai S, Ohkawa S, Sugimasa Y, et al. Close association between high serum ALT and more rapid recurrence of hepatocellular carcinoma in hepatectomized patients with HCV-associated liver cirrhosis and hepatocellular carcinoma. Intervirology. 2000;43:20-26.

30. Tarao K, Takemiya S, Tamai S, Sugimasa Y, Ohkawa S, Akaike M, et al. Relationship between the recurrence of hepatocellular carcinoma (HCC) and serum alanine aminotransferase levels in hepatectomized patients with hepatitis C virus-associated cirrhosis and HCC. Cancer. 1997;79:688694.

31. Shirabe K, Takenaka K, Taketomi A, Kawahara N, Yamamoto K, Shimada M, et al. Postoperative hepatitis status as a significant risk factor for recurrence in cirrhotic patients with small hepatocellular carcinoma. Cancer. 1996;77:1050-1055.

32. Hernandez-Gea V, Toffanin S, Friedman SL, Llovet JM. Role of the microenvironment in the pathogenesis and treatment of hepatocellular carcinoma. Gastroenterology. 2013;144:512-527.

33. Budhu A, Forgues M, Ye QH, Jia HL, He P, Zanetti KA, et al. Prediction of venous metastases, recurrence, and prognosis in hepatocellular carcinoma based on a unique immune response signature of the liver microenvironment. Cancer Cell. 2006;10:99-111.

34. Matsumoto K, Yoshimoto J, Sugo H, Kojima K, Futagawa S, Matsumoto T. Relationship between the histological degrees of hepatitis and the postoperative recurrence of hepatocellular carcinoma in patients with hepatitis C. Hepatol Res. 2002;23:196-201.

35. Liu Y, Wang ZX, Cao Y, Zhang G, Chen WB, Jiang CP. Preoperative inflammation-based markers predict early and late recurrence of hepatocellular carcinoma after curative hepatectomy. Hepatobiliary Pancreat Dis Int. 2016;15:266-274.

36. Lu LH, Zhang YF, Wei W, Shi M, Guo RP. Preoperative Carbohydrate Antigen 19-9: Its Neglected Role in Alpha-Fetoprotein-Negative Hepatocellular Carcinoma Patients. J Gastrointest Surg. 2017;21:20252032.

\section{Figures}


a

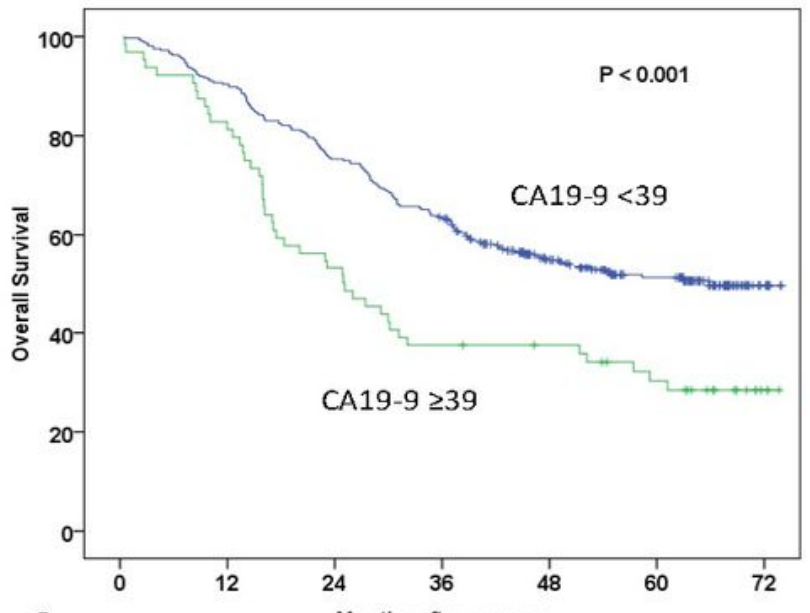

C
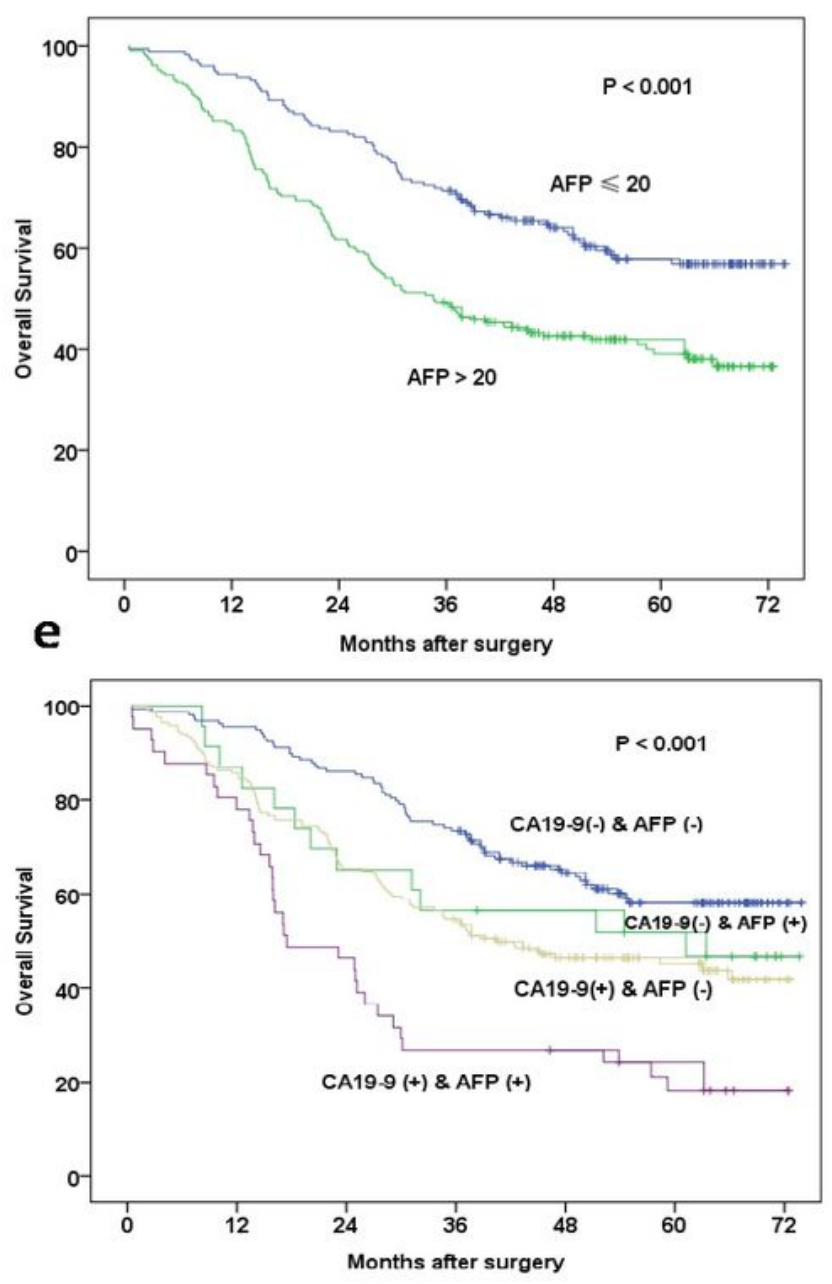

b
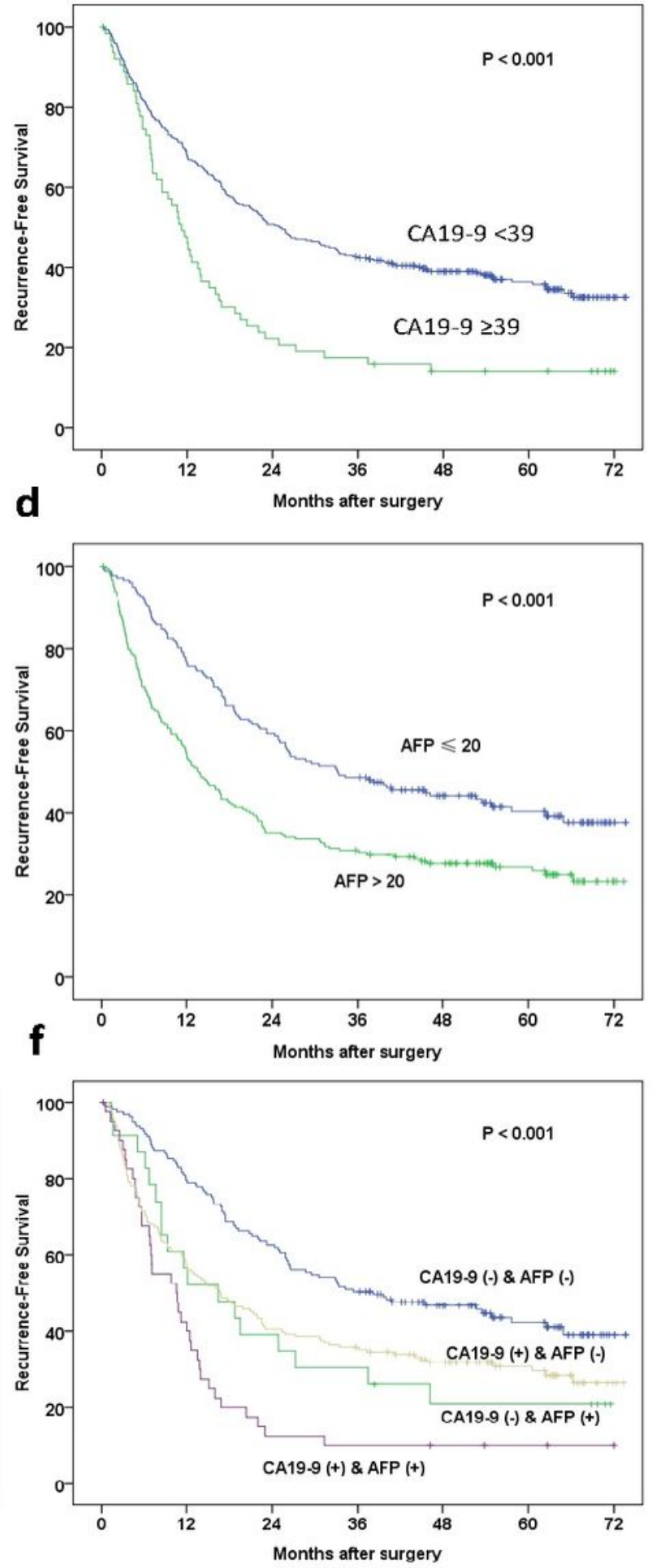

\section{Figure 1}

AFP, CA19-9 and combination to predict OS and RFS for HCC patients after curative resection. 


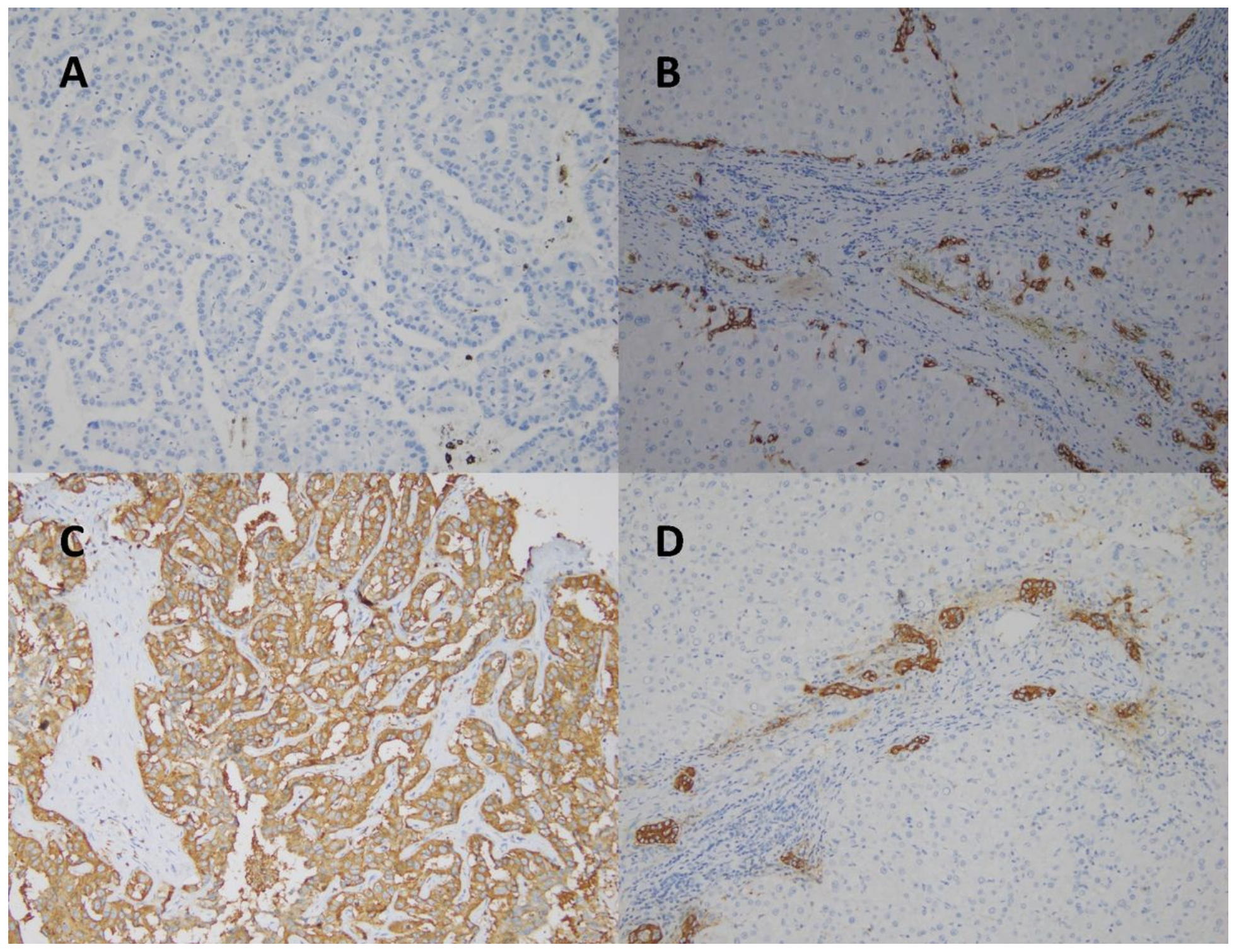

\section{Figure 2}

Immunohistochemical staining of CA19-9 in HCC and ICC in Cohort 2 and 3. A, HCC tumor tissue was negative for CA19-9. B, HCC non-tumor liver parenchyma was positive for CA19-9 in the portal area. C, ICC tumor tissue was positive for CA19-9. D, Positive staining of CA19-9 in the portal area in non-tumor liver parenchyma of ICC. 

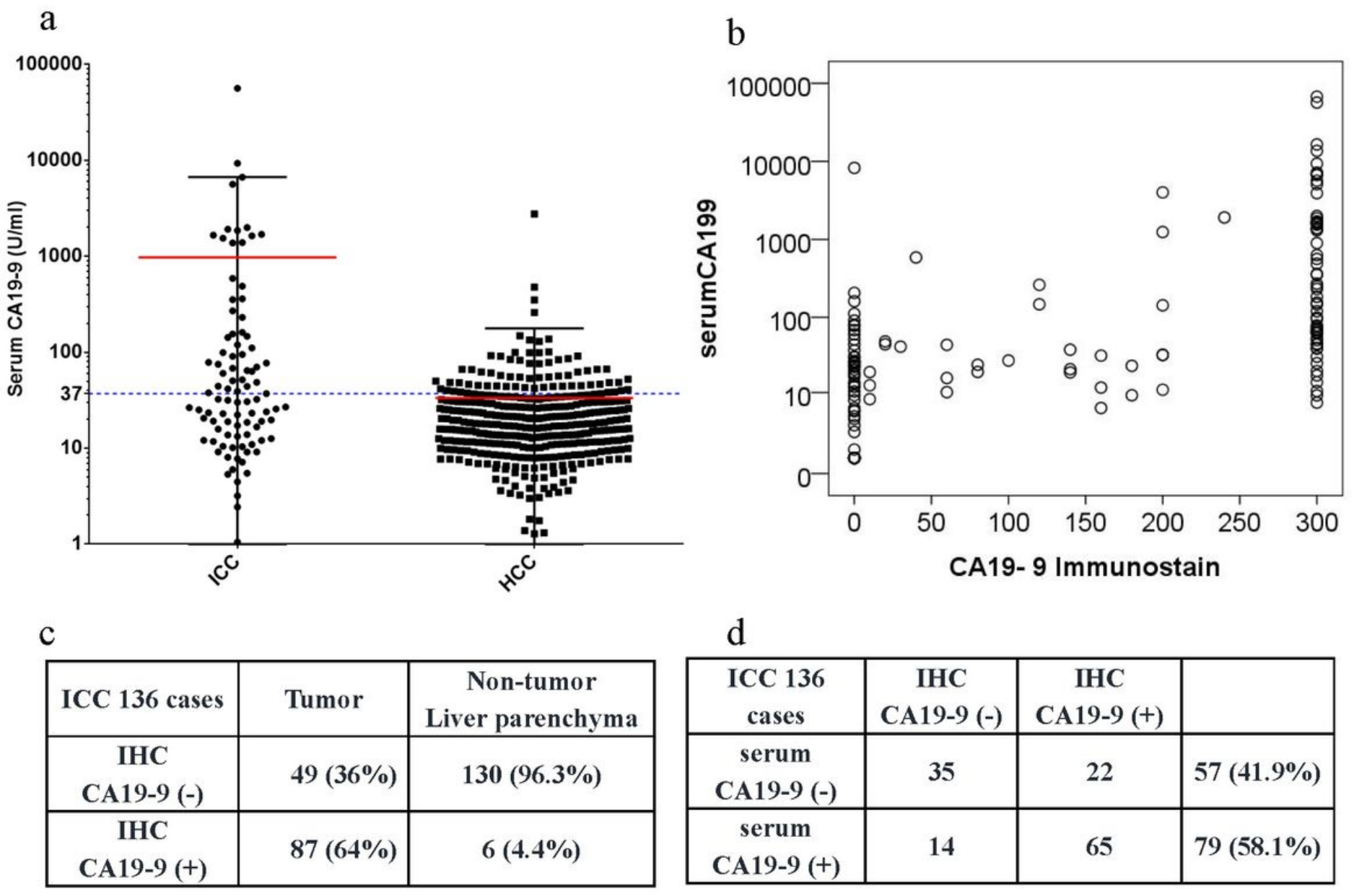

C
\begin{tabular}{|c|c|c|}
\hline ICC 136 cases & Tumor & $\begin{array}{c}\text { Non-tumor } \\
\text { Liver parenchyma }\end{array}$ \\
\hline $\begin{array}{c}\text { IHC } \\
\text { CA19-9 (-) }\end{array}$ & $49(36 \%)$ & $130(96.3 \%)$ \\
\hline $\begin{array}{c}\text { IHC } \\
\text { CA19-9 }(+)\end{array}$ & $87(64 \%)$ & $6(4.4 \%)$ \\
\hline
\end{tabular}

$\mathrm{d}$
\begin{tabular}{|c|c|c|c|}
\hline $\begin{array}{c}\text { ICC } 136 \\
\text { cases }\end{array}$ & $\begin{array}{c}\text { IHC } \\
\text { CA19-9 (-) }\end{array}$ & $\begin{array}{c}\text { IHC } \\
\text { CA19-9 (+) }\end{array}$ & \\
\hline $\begin{array}{c}\text { serum } \\
\text { CA19-9 (-) }\end{array}$ & 35 & 22 & $57(41.9 \%)$ \\
\hline $\begin{array}{c}\text { serum } \\
\text { CA19-9 (+) }\end{array}$ & 14 & 65 & $79(58.1 \%)$ \\
\hline
\end{tabular}

\section{Figure 3}

CA19-9 in HCC and ICC in Cohort 2 and 3. a, comparison of serum CA19-9 level in ICC and HCC patients. b, Serum CA19-9 correlated with IHC CA19-9 in Cohort 3 ( $p<0.001)$. c, Immunohistochemical staining of CA19-9 in ICC tumor and non-tumor liver parenchyma showed that CA19-9 is positive in $64 \%$ in tumor tissue and $4.4 \%$ in non-tumor liver parenchyma. $d$, comparison between serum CA19-9 and immunochemical staining of CA19-9 in ICC patients. 